\title{
Ebola, Ethics, and the Question of Culture
}

\author{
Paul Komesaroff • Ian Kerridge
}

Received: 21 September 2014 / Accepted: 29 September 2014

(C) Journal of Bioethical Inquiry Pty Ltd 2014

The Ebola virus disease (EVD) epidemic in Western Africa has, in recent months, aroused growing alarm in Western countries. Attention has been drawn to the threat posed to the inhabitants of the region by what has undoubtedly become a major health emergency. As the death toll has mounted, increasingly strident calls for action have been voiced by nongovernmental organizations (NGOs) and international agencies active in the area, such as Médecins Sans Frontières and the World Health Organization and, more recently, even by the U.S. president.

Critics of the Western response have claimed that the newfound concern about EVD, which has been present in Africa for nearly 40 years, reflects a longstanding disregard of the needs of people living in the region. They point out that the difficulties in controlling the spread of the disease are in large part due to the lack of effective health infrastructure, which in turn reflects global disparities in wealth and opportunity. Despite the lack of major technical obstacles, they argue further, there has been little scientific research into methods for treating or preventing the disease and that it has only been when Western interests, and Western citizens, have

P. Komesaroff $(\square)$

Centre for Ethics in Medicine and Society, Monash University

Faculty of Medicine, Nursing and theHealth Sciences,

Melbourne, Australia

e-mail: paul.komesaroff@monash.edu

\section{Kerridge}

Centre for Values, Ethics and the Law in Medicine, Sydney School of Public Health, Medical Foundation Building, University of Sydney,

Sydney, Australia been threatened that the developed world has been prompted to act.

Questions also have been raised about the ethics of infectious diseases more generally, such as the limits of the responsibility of health care workers subjected to personal danger, the scope of restrictive measures to control outbreaks, the allocation of scarce resources, and the evaluation of global responses. Other concerns are more specific to the cultural context of Western Africa. These, in turn, vary from the impact of the disease on local cultural practices and lifeworld experiences to the risks that the militarised responses to it might be used to justify increasingly oppressive political regimes.

There is certainly truth in these criticisms, which draw attention to the extent to which ethical questions are conditioned by, and subject to, cultural difference. The articles addressing the EVD epidemic by Peter Omonzejele (2014) and Ross Upshur (2014) in this issue of the Journal of Bioethical Inquiry further exemplify the cultural dependence of ethical reflection and demonstrate how ethical discourses that proceed from different cultural starting points can generate disparate outcomes. They also illustrate how different arguments, equally cogent and coherent in their own settings, can employ strikingly different approaches and assumptions and how the framing of the ethical questions can determine the conclusions.

Upshur's article addresses "large-scale" questions about global policies: for example, transparency of access to and rapid deployment of "novel therapies," the issue of precedent, and trans-border risks. While these are very important concerns, the arguments inherently arise from the point of view of the generalised, theoretical subject or, rather, from theory itself. Upshur formulates his questions by reference to a lexicon of concepts 
deriving from a particular cultural context and depending for their authority on assumptions about the local and globalised force of particular ideas and styles of argument. Taking for granted the appropriateness of the high level of abstraction, he moves easily within an unquestioned space of theoretical deliberation. The article connects with the specificity of the Ebola problem principally through an acknowledgement of local public health implications, on the one hand, and a broad argument about the concept of "compassion," on the other. Interestingly, however, both of these are in reality still highly abstract; what is more, the concept of "compassion" itself, with its implicit references to the dialectic between suffering and purification, is deeply rooted in Judeo-Christian traditions of thought.

Omonzejele's article, by contrast, focuses on the direct and concrete ways in which EVD has disrupted the personal and cultural lifeworlds of the people of Western Africa. He identifies local practices - including those embedded in intimate relationships and traditional practices - that have themselves been infected with or infiltrated by the virus, with consequences that are yet to be elaborated. In relation to the question of the availability of inadequately tested or untested drugs, instead of "compassion" Omonzejele refers to the concept of whether the use of an experimental drug is "compelling" and then connects this with the historical experience of abuse of power and privilege. In other words, his understanding of philosophical terms is itself conditioned by the colonial relations of power.

Each article raises its own questions: Omonzejele's article draws attention to the potential implications of changes in death rites and associated practices for social cohesion and stability, while Upshur's highlights concerns about the impact of the crisis on the policies and aid practices of international agencies.

A question also arises of the relationship between the two articles, which is not straightforward. Although the arguments are not obviously in contradiction to each other, it is not inconceivable that they could have led to opposing positions: For example, Upshur could have argued (although he does not do so) that extraordinary military measures and the expenditure of billions of dollars on a military apparatus were needed to protect countries not yet affected by the epidemic, a position that would likely have been inimical to Omonzejele's concerns to protect the integrity of local lifeworld experiences.
It is not satisfactory to claim merely that the arguments are "complementary." They arise from and exemplify different-maybe incommensurable-epistemological frameworks. They deploy dramatically different discourses, identify different problems, and lead to different political projects. Upshur remains firmly rooted within a Western problematic and reflects contemporary concerns with global health, while Omonzejele's perspective is strikingly "local" and his arguments reflective of the "everyday" experience of people living in communities in Sierra Leone, Liberia, Guinea, and Nigeria.

The main point is to recognise that any perspective assumes a particular view of the world, utilises a particular methodology, and comes with consequencessome of which may be unintended. Even an apparently incontestable claim - that the Ebola epidemic needs to be contained - might set in motion a theoretical chain that inexorably supports effete colonial power structures and generates enduring adverse cultural outcomes. The Ebola epidemic, perhaps more than any other, reminds us that ethical questions depend on the positions and social roles of the persons asking the questions and what decisions they are in a position to make. And this, in turn, reflects social and political relationships of power and privilege, as well as epistemologies and culturally derived value frameworks.

Ethics in not a single, undifferentiated, monolithic body of thought, but rather a collection of methods and perspectives that convey different efficacy for actors in different settings. This is not an argument in favour of what is often (disparagingly) referred to as "relativism." Rather, it is a reminder that the universalising points of view of bioethics have to retain within their own theory a conscious awareness of their conditions of knowledge and the limits of the claims they might make. There is no escape from the entrapment of ethics within the contexts of specific cultural settings and lifeworlds.

\section{References}

Omonzejele, P.F. 2014. Ethical challenges posed by the Ebola virus epidemic in West Africa. Journal of Bioethical Inquiry 11(4). doi:10.1007/s11673-014-9586-4.

Upshur, R.E.G. 2014. Ebola virus in West Africa: Waiting for the owl of Minerva. Journal of Bioethical Inquiry 11(4). doi:10. 1007/s11673-014-9580-x. 